\title{
Early detection and intervention of psychosis in children and adolescents: urgent need for studies
}

\author{
Benno G. Schimmelmann • Frauke Schultze-Lutter
}

Published online: 18 April 2012

(C) Springer-Verlag 2012

Psychotic disorders, particularly of the schizophreniaspectrum, are among the most severe mental diseases. They can lead to delays in the maturation of neuropsychological functions in affected children and adolescents and longterm neuropsychological deficits $[1,2]$ as well as significant impairments in psychosocial functioning [3]. This makes schizophrenia one of the six leading causes of years lived with disability [4]. To fight the devastating consequences of psychotic disorders, two strategies have been followed with great enthusiasm and hope over the last 15 years.

One strategy is to detect the disorder as early as possible, i.e., to reduce the duration of untreated psychosis and, consequently, to adequately treat the disorder as soon as possible with an early and specialized intervention. Notably, it was assumed for a long time that an adolescent onset of psychosis (before age 18, EOP) is associated with worse outcomes compared to adult-onset psychosis (AOP; [5]). However, two recent studies comparing EOP (age 14-17) with AOP (age 18-30) did not support this assumption. They indicated that EOP when also treated in an early psychosis, prevention and intervention centre have similar short-term [6] and similar or even better long-term outcomes [7]. Most recently, an independent comparative population based study conducted in a different centre confirmed these findings [8]. It still remains to be shown whether specialized early detection and intervention indeed causes the similar or even better outcomes of EOP. Despite the face validity of early intervention, it is not yet clear for patients with AOP that early intervention is superior to

B. G. Schimmelmann $(\bowtie) \cdot$ F. Schultze-Lutter

University Hospital of Child and Adolescent Psychiatry, University of Bern, Bolligenstr. 110, 3000 Bern 60, Switzerland e-mail: bschimme@aol.com treatment-as-usual for patients with AOP. A recent Cochrane review concluded that there is some support for the superior effectiveness of early intervention, but that further studies are desirable, and that it is questionable whether gains are maintained [9]. Regarding early intervention strategies, it is generally recommended that an early intervention service should be provided longer than 2 years [10] or, alternatively, new strategies should be developed to produce more sustainable effects of short-term intensive early intervention programs. For children and adolescents with EOP, studies on the effectiveness of such programs or special needs within these programs are necessary. While initial evidence suggests that early intervention works in adolescents [7], the duration of untreated psychosis was found to be clearly longer in adolescents than in adults despite early detection efforts [11, 12]. However, the reasons for this are not known. Potential reasons are: insufficient knowledge about psychotic symptoms in the respective health care service (including child and adolescent psychiatry/psychology); a more insidious onset of symptoms; more negative symptoms; higher rates of refusal to seek help, and overlooking symptoms or misinterpreting them as adolescent crisis by parents and teachers.

The second strategy to improve outcome of psychotic disorders is to detect early signs of the emerging disorder before sustained psychotic symptoms occur. While a prodrome may include rather unspecific symptoms and can only safely be diagnosed in retrospect, research over the last 15 years has brought about two rather specific sets of at-risk criteria for psychotic disorders, the ultra-high risk criteria (including attenuated psychotic symptoms, APS; brief limited intermittent symptoms, BLIPS) and the basic symptom criteria (including cognitive-perceptive symptoms, COPER; cognitive disturbances, COGDIS). The presence of one of these criteria is associated with an about 
$20 \%$ risk of conversion to psychosis in help-seeking adults in the following year [13]. This research, in mostly adult samples, led to the proposal of an Attenuated Psychosis Syndrome for inclusion in DSM-5 [14]. In this journal, 1 year ago, Arango [15] carefully weighed the risks and benefits for children and adolescents of including the Attenuated Psychosis Syndrome in DSM-5, and made the point that APS must also be considered in developmental terms. APS are not sufficiently validated in children and adolescents in terms of conversion to psychosis or disease status at all. As the Attenuated Psychosis Syndrome includes only one out of three UHR and none of the basic symptom criteria, future research on the early detection of psychosis in children and adolescents must take a broader perspective. The following questions should be addressed:

1. Predictive validity of current at-risk criteria in children and adolescents: To date, only two rather small studies assessed conversion rates exclusively in children and adolescents. Cornblatt [16] (48, 12- to 18-year-old, adolescents with attenuated psychotic symptoms) reported that at-risk adolescents converted to psychosis later than expected from studies of adults. However, Ziermans [17] (58, 12- to 18-year-old, adolescents with UHR criteria or COGDIS) reported that the conversion rate was slightly lower but not delayed compared to adults (16\% in 2 years). Data on children below age 12 are not available.

2. Assessment issues: Apart from the schizophrenia proneness instrument-child and youth version (SPICY; [18]) for the assessment of basic symptoms in children and adolescents (age 8-17), no age-adapted tools for the assessment of the other at-risk criteria in children and adolescents exist. As most studies on adults included some adolescents ( $\geq$ age 15), it is probably safe to use current assessment tools in this age group (e.g., SIPS [19] or CAARMS [20]); whereas, it is not known whether at-risk criteria are valid in this age group. However, it is unclear (1) at what age children are able to provide reliable account of at-risk symptoms, (2) when and how parental reports should be considered, and (3) how a differential diagnosis to relevant child and adolescent psychiatric disorders should be made (e.g., autism spectrum disorders).

3. Significance of at-risk symptoms in the general population of children and adolescents: To date, it is not fully understood whether at-risk symptoms are so common among children and adolescents that a valid distinction between ill and non-ill youngsters is difficult [21]. This question came into focus with several studies in adults and children that report high rates of standardized lay person or self-report assessed psychotic-like experiences in the general population [15]. However, only three studies addressed this question to date in adults [22] and adolescents [3, 23] using appropriate clinical assessments of atrisk criteria. All the three studies found rather low rates of APS or BLIPS in children (age 11-13; 0.9-8.1\% depending on UHR definition [23]) or adults (age 16-40; 0-2 \% [22]) as well as COPER $(<3 \%)$ and COGDIS $(<8.0 \%)$ in adolescents [13]. Notably, in children and adolescents, $63 \%$ of adolescents with APS or BLIPS met criteria for at least one past or present axis-I diagnosis according to DSM-IV [23]. They also had poorer psychosocial functioning than the control group. In the pilot-study on adults, similar findings were reported [22]. These rather preliminary findings support the notion that current at-risk criteria, if carefully assessed, are less prevalent than expected from studies on psychotic-like experiences and related to some impairment. Furthermore, the clinical relevance of (atypical) psychotic symptoms in children and their predictive validity for a psychotic disorder is still not fully understood. While several studies confirm the transient and atypical nature of (atypical) psychotic symptoms in children with low conversion rates to psychotic disorders [24-26], the Dunedin birth cohort study reported that psychotic symptoms at age 11 predicted the emergence of a schizophreniform disorder at age 26, but also of an anxiety disorder [27].

Regarding clinical implications, child and adolescent psychiatry is far from having a sufficient evidence base for creating appropriate strategies for the early detection and early intervention in psychosis in this age group. However, regarding early intervention, initial evidence suggests that adolescents (age 14-17) benefit from early intervention programs to a degree that is comparable to the benefit of young adults [6, 7]. Yet, age-appropriate early detection strategies may be necessary to reduce the duration of untreated psychosis in adolescents. The early detection of psychosis in the prodromal stage is difficult in both adults and children/adolescents. However, the proposal of an Attenuated Psychosis Syndrome for inclusion in DSM-5 reflects the fact that patients with APS indeed experience distress and significant impairment, so that treatment seems justified independent of conversion risk to psychosis. While the evidence is sparse, our experience is that this may also be true in children and adolescents. They (and their parents or carers) suffer from at-risk symptoms, appreciate their competent assessment and are interested in focusing on them in the treatment process, independent of conversion risk. The concern that an increased use of antipsychotics in children and adolescents might follow the introduction of a non-validated Attenuated Psychosis 
Syndrome, voiced by Arango [15], may be true. However, the availability of a child and adolescent psychiatrist with special training and sufficient experience in the assessment of at-risk symptoms in this age group will be most welcomed in the mental health system. This would prevent an unjustified and potentially stigmatizing, yet commonly encountered pseudo-diagnosis of "pre-psychotic" or "prodromal" for these patients, and may thereby limit premature or prolonged use of antipsychotics. To this, it is recommended that adult and child and adolescent psychiatrists work together in a team and that the clinical significance and predictive validity of current at-risk criteria in children and adolescents is further studied.

\section{References}

1. Jepsen JR, Fagerlund B, Pagsberg AK, Christensen AM, Nordentoft M, Mortensen EL (2010) Deficient maturation of aspects of attention and executive functions in early onset schizophrenia. Eur Child Adolesc Psychiatry 19(10):773-786

2. Jepsen JR, Fagerlund B, Pagsberg AK, Christensen AM, Hilker RW, Nordentoft M, Mortensen EL (2010) Course of intelligence deficits in early onset, first episode schizophrenia: a controlled, 5-year longitudinal study. Eur Child Adolesc Psychiatry 19(4): 341-351

3. Meng H, Schimmelmann BG, Koch E, Bailey B, Parzer P, Günter M, Mohler B, Kunz N, Schulte-Markwort M, Felder W, Zollinger R, Bürgin D, Resch F (2009) Basic symptoms in the general population and in psychotic and non-psychotic psychiatric adolescents. Schizophr Res 111(1-3):32-38

4. WHO (2004) Prevention of mental disorders, WHO, Geneva

5. Fleischhaker C, Schulz E, Tepper K, Martin M, Hennighausen K, Remschmidt H (2005) Long-term course of adolescent schizophrenia. Schizophr Bull 31(3):769-780

6. Schimmelmann BG, Conus P, Cotton S, McGorry PD, Lambert M (2007) Pre-treatment, baseline, and outcome differences between early-onset and adult-onset psychosis in an epidemiological cohort of 636 first-episode patients. Schizophr Res 95 (1-3): $1-8$

7. Amminger GP, Henry LP, Harrigan SM, Harris MG, AlvarezJimenez M, Herrman H, Jackson HJ, McGorry PD (2011) Outcome in early-onset schizophrenia revisited: findings from the early psychosis prevention and intervention centre long-term follow-up study. Schizophr Res 131(1-3):112-119

8. Langeveld J, Joa I, Friis S, Ten Velden Hegelstad W, Melle I, Johannessen JO, Opjordsmoen S, Simonsen E, Vaglum $\mathrm{P}$, Auestad B, McGlashan T, Larsen TK (2012) A comparison of adolescent- and adult-onset first-episode, non-affective psychosis: 2-year follow-up. Eur Arch Psychiatry Clin Neurosci. doi:10. 1007/s00406-012-0308-9

9. Marshall M, Rathbone J (2011) Early intervention for psychosis. Schizophr Bull 37(6):1111-1114

10. Skalli L, Nicole L (2011) Specialised first-episode psychosis services: a systematic review of the literature. Encephale 37 (Suppl 1):S66-S76

11. Joa I, Johannessen JO, Langeveld J, Friis S, Melle I, Opjordsmoen S, Simonsen E, Vaglum P, McGlashan T, Larsen
TK (2009) Baseline profiles of adolescent vs. adult-onset firstepisode psychosis in an early detection program. Acta Psychiatr Scand 119(6):494-500

12. Schimmelmann BG, Huber CG, Lambert M, Cotton S, McGorry PD, Conus P (2008) Impact of duration of untreated psychosis on pre-treatment, baseline, and outcome characteristics in an epidemiological first-episode psychosis cohort. J Psychiatr Res 42(12):982-990

13. Schultze-Lutte F, Ruhrmann S, Fusar-Poli P, Schimmelmann BG, Klosterkötter J (2012) Basic symptoms and the prediction of firdtepiode psychosis. Curr Pharm Des 18(4):351-357

14. American Psychiatric Association (2011) Proposed draft revisions to DSM disorders and criteria: attenuated psychotic symptoms syndrome. http://www.dsm5.org/ProposedRevisions/Pages/ proposedrevision. aspx?rid=412. Accessed 19 December 2011

15. Arango C (2011) Attenuated psychotic symptoms syndrome: how it may affect children and adolescent psychiatry. Eur Child Adolesc Psychiatry 20(2):67-70

16. Cornblatt BA, Lencz T, Smith CW, Olsen R, Auther AM, Nakayama E, Lesser ML, Tai JY, Shah MR, Foley CA, Kane JM, Correll CU (2007) Can antidepressants be used to treat the schizophrenia prodrome? Results of a prospective, naturalistic treatment study of adolescents. J Clin Psychiatry 68(4):546-557

17. Ziermans TB, Schothorst PF, Sprong M, van Engeland H (2001) Transition and remission in adolescents at ultra-high risk for psychosis. Schizophr Res 126(1-3):58-64

18. Schultze-Lutter F, Marshall M, Koch E (2012) Schizophrenia Proneness Instrument, Child \& Youth version, Extended English Translation (SPI-CY EET). Rom, Giovanni Fioriti Editore s.r.l (in press)

19. McGlashan T, Walsh B, Woods S (2010) The Psychosis-risk syndrome. Handbook for diagnosis and follow-up. Oxford University Press, New York

20. Yung AR, Phillips LJ, Simmons MB, Ward J, Thompson P, French P, McGorry P (2006) Comprehensive Assessment of At Risk Mental States (CAARMS). The PACE Clinic, ORYGEN Research Centre, University of Melbourne, Department of Psychiatry, Parkville, Victoria

21. Carpenter WT (2009) Anticipating DSM-V: should psychosis risk become a diagnostic class? Schizophr Bull 35(5):841-843

22. Schimmelmann BG, Michel C, Schaffner N, Schultze-Lutter F (2011) What percentage of people in the general population satisfies the current clinical at-risk criteria of psychosis? Schizophr Res 125(1):99-100

23. Kelleher I, Murtagh A, Molloy C, Roddy S, Clarke MC, Harley M, Cannon M (2011) Identification and characterization of prodromal risk syndromes in young adolescents in the community: a population-based clinical interview study. Schizophr Bull 38 (2):239-246

24. Bartels-Velthuis AA, Jenner JA, van de Willige G, van Os J, Wiersma D (2010) Prevalence and correlates of auditory vocal hallucinations in middle childhood. Br J Psychiatry 196(1):41-46

25. Bartels-Velthuis AA, van de Willige G, Jenner JA, van Os J, Wiersma D (2011) Course of auditory vocal hallucinations in childhood: 5-year follow-up study. Br J Psychiatry 199(4): 296-302

26. Hlastala SA, McClellan J (2005) Phenomenology and diagnostic stability of youths with atypical psychotic symptoms. J Child Adolesc Psychopharmacol 15(3):497-509

27. Poulton R, Caspi A, Moffitt TE, Cannon M, Murray R, Harrington H (2000) Children's self-reported psychotic symptoms and adult schizophreniform disorder: a 15-year longitudinal study. Arch Gen Psychiatry 57(11):1053-1058 